\title{
The effect of preventative cardiovascular therapies on coronary artery disease in people with and without type 2 diabetes: a propensity-matched score study
}

Katerina V. Kiburg 1,2,3*0, Andrew I. Maclsaac ${ }^{2,4}$, Georgia E. McCluskey ${ }^{1}$, Vijaya Sundararajan ${ }^{5 \dagger}$ and Richard J. Maclsaac 1,2,3†

\begin{abstract}
Background: Although it is known that patients with Type 2 Diabetes Mellitus (T2DM) are at an increased risk of coronary artery disease (CAD), the actual coronary artery burden of atherosclerotic disease in patients with and without T2DM in a real-world setting and its possible modification by preventative therapies has not been extensively documented.

Methods: Merged coronary angiography and hospital discharge data between 2013 and 2019 were obtained for analysis and a random sub-sample of patient charts were reviewed for medication use. Propensity scores were estimated using logistic regression models and used to match patients, looking at the effect of severity of CAD over time in years in an ordinal logistic regression model. A separate propensity score was estimated and used to inverse probability weight the ordinal logistic regression looking at the effect of medication use on CAD severity in patients with and without T2DM.

Results: From 3,016 patients in the coronary angiography database, 1421 with T2DM and 1421 without T2DM were matched on propensity score. T2DM patients had more extensive CAD in 2018 compared to 2013 ((adjusted odds ratio) adjOR: $2.0695 \%$ C.I. 1.38, 2.07), but this risk appeared to be attenuated in 2019. In contrast, there was no effect of time on CAD burden in patients without diabetes. In the sub-sample of 760 patients who underwent a chart review of their medication use, there were 367 (48\%) with T2DM. For patients with T2DM 69.8\% reported taking statins, 64.0\% RAS inhibitors and $64.0 \%$ anti-platelet drugs. This was significantly higher than patients without diabetes of whom 46.6\% reported taking statins, 49.0\% RAS inhibitors and 49.9\% anti-platelet drugs. As in the full matched sample, patients with diabetes had more extensive CAD (adjOR: 1.32 95\% Cl: 1.01, 1.74). However, after adjustment for the use of RAS inhibitors, statins and anticoagulants there was no difference in extent of CAD between patients with and without diabetes (adjOR: 1.14 95\% Cl: 0.85, 1.53).
\end{abstract}

Conclusions: Although patients with diabetes have a greater extent of CAD in comparison to those without T2DM, preventative medication use decreases this CAD burden significantly.

\footnotetext{
*Correspondence: katerina.kiburg@svha.org.au

${ }^{\dagger}$ Vijaya Sundararajan and Richard J. Maclsaac equal senior authors

1 Department of Endocrinology and Diabetes, St Vincent's Hospital

Melbourne, Fitzroy, VIC, Australia

Full list of author information is available at the end of the article
}

(C) The Author(s) 2021. Open Access This article is licensed under a Creative Commons Attribution 4.0 International License, which permits use, sharing, adaptation, distribution and reproduction in any medium or format, as long as you give appropriate credit to the original author(s) and the source, provide a link to the Creative Commons licence, and indicate if changes were made. The images or other third party material in this article are included in the article's Creative Commons licence, unless indicated otherwise in a credit line to the material. If material is not included in the article's Creative Commons licence and your intended use is not permitted by statutory regulation or exceeds the permitted use, you will need to obtain permission directly from the copyright holder. To view a copy of this licence, visit http://creativecommons.org/licenses/by/4.0/. The Creative Commons Public Domain Dedication waiver (http://creativeco mmons.org/publicdomain/zero/1.0/) applies to the data made available in this article, unless otherwise stated in a credit line to the data. 
Keywords: Type 2 diabetes, Coronary artery disease, Coronary angiogram, Epidemiology

\section{Background}

Patients with diabetes are known to be at an increased risk for developing coronary artery disease (CAD) compared to patients with normoglycaemia. A number of studies over the past decades have shown that the management of cardiometabolic risk factors including hyperglycaemia, dyslipidemia, and hypertension through intensive multifactorial interventions reduce the development and progression of diabetes related macrovascular complications [1-5]. Despite this, cardiovascular (CV) disease continues to be the leading cause of death for adult patients with type 2 diabetes mellitus (T2DM) and represents a substantial economic burden to both the patient and population [6,7]. Whilst there have been a large number of clinical studies documenting the relatively poorer $\mathrm{CV}$ outcomes for patients with diabetes, there have been few studies that have examined the impact of diabetes on coronary artery anatomy. In particular, the extent of CAD involvement for patients with and without diabetes and the impact of traditional $\mathrm{CV}$ disease preventative therapies on disease within the coronary arteries, as assessed by angiography, has not been well characterised over the past 10 years. We have therefore evaluated the severity of CAD based on coronary angiogram for patients with and without T2DM admitted to a tertiary hospital in Australia over the seven-year period between 2013 and 2019. We hypothesis that people with diabetes will have a greater burden of atherosclerosis within their coronary arteries compared to those without diabetes, even following adjustment for the use of traditional $\mathrm{CV}$ protective medications.

\section{Methods}

\section{Setting and data sources}

All patient coronary angiography and hospital discharge data at a large Australian tertiary referral hospital between 2013 and 2019 were obtained and merged using the hospital record number. A random stratified sample of these patient charts were reviewed for medication use (renin-angiotensin system (RAS) inhibitors,

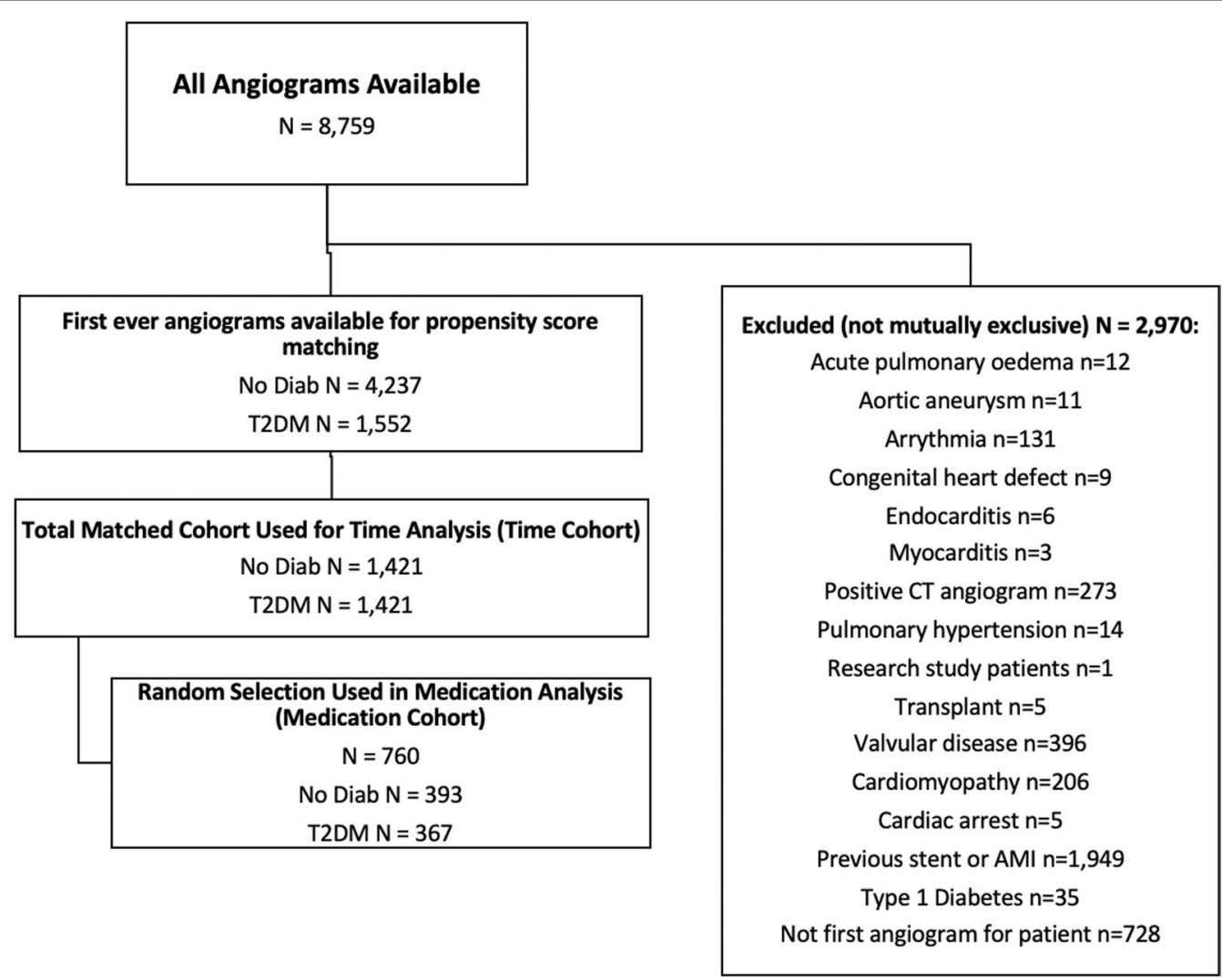

Fig. 1 Flow chart of cohort numbers 
statins, anti-platelet drugs and medications related to diabetes management), with $50 \%$ of charts selected based on T2DM diagnosis (Fig. 1). Diagnostic information is coded according to the International Statistical Classification of Diseases and Related Health Problems, Australian Modification (ICD-10-AM) [8].

\section{Case definition}

A patient's first known angiogram at the hospital was included. Indication for angiography was based on the original classification by treating cardiologist and included: chest pain, history of an acute coronary event, breathlessness, positive non-invasive test and other indications for angiogram which could not be directly linked with atherosclerotic disease. The sample was restricted to angiograms for the above indication and excluded angiograms performed for the following indications: acute pulmonary oedema, aortic aneurysm, arrhythmia, cardiac arrest, cardiomyopathy, congenital heart defect, endocarditis, myocarditis, positive CT coronary angiogram, previous myocardial infarction, previous stent, pulmonary hypertension, research study patients, transplant work-up or valvular disease. A diagnosis of T2DM was established using ICD-10-AM codes E11.0 to E11.9. Angiograms for patients with a diagnosis of type 1 diabetes using ICD-10-AM codes E10 were excluded.

\section{Main outcome}

The main outcome was the extent of CAD based on the original classification by treating cardiologists: no disease, mild disease, moderate disease or severe disease. Although grading of the extent of CAD was at the discretion of the treating cardiologist, patients with mild disease had minor coronary disease without any evidence of significant vessel stenosis, those with moderate disease had at least one vessel with greater than $50 \%$ stenosis, and those with severe disease had two or three vessels with greater than $50 \%$ stenosis.

\section{Statistical analysis}

To reduce potential confounding factors in the sample, we used the propensity score in two ways: to match and to inverse probability weight, further detail Additional file 2 . The propensity scores were estimated using logistic regression models and included baseline patient characteristics (age, gender, country of birth (Australian $\mathrm{y} / \mathrm{n}$ ), English spoken $(y / n)$, indication for angiogram, year of coronary angiogram, Socio-Economic Indexes for Areas (SEIFA) index (a measure of relative socio-economic disadvantage, Additional file 2) and Elixhauser comorbidities (a measure of patients disease burden using hospital administrative data) [9]. Standardised differences were calculated for each baseline patient characteristic variable, with all standardised differences being $<0.1$ [10]. One propensity score was developed to identify a $1: 1$ matched sample of patients with and without T2DM in the time analysis with a prespecified caliper of 0.01 (the time cohort) and a second propensity score was developed to inverse probability weight the sub-sample which underwent chart review for their medication use (the medication cohort, see Fig. 1).

Continuous variables are presented as median (interquartile range) and categorical variables as total number and percentage (\%). Patient characteristics by diabetes status were compared using Wilcoxon rank-sum test for continuous variables and Pearson's $\chi^{2}$ for categorical variables.

An ordinal logistic regression model stratified by T2DM status was fitted to estimate effect of T2DM on the severity of CAD (none, mild, moderate or severe) over time in years in the matched sample, the time cohort. A separate ordinal logistic regression model was fitted to estimate the average treatment effect among the treated on the random sample of patients who had their charts reviewed for medication use, the medication cohort [11]. All analyses were conducted using STATA version 16.1 (StataCorp, College Station, TX).

\section{Results}

Baseline patient characteristics of the study population are shown in Additional file 1: Table S1. Of first angiograms 1572 (27.2\%) had T2DM. Patients with T2DM were significantly older, less likely to be born in Australia, less likely to speak English and had greater numbers of co-morbid conditions than those without T2DM. There were no significant differences in the indication for coronary angiography in patients with and without T2DM: chest pain, $22 \%$ versus 22\%; history of Acute Coronary Event (ACS), 9\% versus 10\%; breathlessness, $8 \%$ versus 9\%; positive non-invasive test, $36 \%$ versus $33 \%$ and other, $26 \%$ versus $27 \%$, respectively.

\section{Time cohort}

Following propensity score matching, there were 1421 matched pairs of patients (Table 1). The median age of patients was 67.3 years (IQR 59.0, 74.7) and 63.2\% (1796) were male. As expected, in the matched cohort there were no significant differences for any of the covariates between patients with and without diabetes.

Additional file 1: Table S2 lists the extent of CAD over time. Figure 2 shows the change in extent of CAD in patients both with and without T2DM over the period of the study. In the ordinal logistic regression, an increasing risk of more extensive CAD was observed between 2013 and 2018 (OR: 2.06 95\% C.I. 1.38, 3.09) 
Table 1 Patient demographics for the time cohort

\begin{tabular}{|c|c|c|c|c|}
\hline Characteristics & No diabetes $(n=1421)$ & T2DM $(n=1421)$ & $\begin{array}{l}\text { Standardised difference } \\
(\%)\end{array}$ & $P$ value \\
\hline Age, median (IQR) & $67.6(58.8,75.5)$ & $67.0(59.1,73.7)$ & 1.9 & 0.22 \\
\hline Gender (Male) & $921(64.8 \%)$ & $875(61.6 \%)$ & 6.7 & 0.07 \\
\hline \multicolumn{5}{|l|}{ Country of birth } \\
\hline Non-Australian & $435(30.6 \%)$ & $432(30.4 \%)$ & 0.5 & \multirow[t]{3}{*}{0.80} \\
\hline Australian & $933(65.7 \%)$ & $929(65.4 \%)$ & 0.6 & \\
\hline Unknown & $53(3.7 \%)$ & $60(4.2 \%)$ & 2.5 & \\
\hline \multicolumn{5}{|l|}{ Language spoken } \\
\hline English & $1253(88.2 \%)$ & $1253(88.2 \%)$ & 0.0 & \multirow[t]{3}{*}{0.93} \\
\hline Not English & $121(8.5 \%)$ & $124(8.7 \%)$ & 0.8 & \\
\hline Unknown & $47(3.3 \%)$ & $44(3.1 \%)$ & 1.2 & \\
\hline SEIFA Index, median (IQR) & $6.0(4.0,7.0)$ & $6.0(4.0,7.0)$ & 0.7 & 0.57 \\
\hline \multicolumn{5}{|l|}{ Stage of CKD } \\
\hline No known CKD & $1343(94.5 \%)$ & 1333 (93.8\%) & 3.0 & \multirow[t]{6}{*}{0.96} \\
\hline CKD stage 2 & $6(0.4 \%)$ & $5(0.4 \%)$ & 1.1 & \\
\hline CKD stage 3 & $41(2.9 \%)$ & $45(3.2 \%)$ & 1.6 & \\
\hline CKD stage 4 & $15(1.1 \%)$ & $18(1.3 \%)$ & 2.0 & \\
\hline CKD stage 5 & $12(0.8 \%)$ & $15(1.1 \%)$ & 2.2 & \\
\hline CKD stage unknown & $4(0.3 \%)$ & $5(0.4 \%)$ & 1.3 & \\
\hline \multicolumn{5}{|l|}{ Indication for angiogram } \\
\hline Chest pain & $317(22.3 \%)$ & $315(22.2 \%)$ & \multirow[t]{5}{*}{0.2} & \multirow[t]{5}{*}{1.00} \\
\hline History of acute coronary event & $120(8.4 \%)$ & $121(8.5 \%)$ & & \\
\hline Breathlessness & $115(8.1 \%)$ & $119(8.4 \%)$ & & \\
\hline Positive non-invasive test & $504(35.5 \%)$ & $506(35.6 \%)$ & & \\
\hline Other & $365(25.7 \%)$ & $360(25.3 \%)$ & & \\
\hline \multicolumn{5}{|l|}{ Year of angiogram } \\
\hline 2013 & $141(9.9 \%)$ & $147(10.3 \%)$ & \multirow[t]{7}{*}{2.0} & \multirow[t]{7}{*}{0.95} \\
\hline 2014 & $210(14.8 \%)$ & $207(14.6 \%)$ & & \\
\hline 2015 & $208(14.6 \%)$ & $206(14.5 \%)$ & & \\
\hline 2016 & $209(14.7 \%)$ & $220(15.5 \%)$ & & \\
\hline 2017 & $229(16.1 \%)$ & $242(17.0 \%)$ & & \\
\hline 2018 & $226(15.9 \%)$ & $209(14.7 \%)$ & & \\
\hline 2019 & $198(13.9 \%)$ & $190(13.4 \%)$ & & \\
\hline Valvular disease & $140(9.9 \%)$ & $145(10.2 \%)$ & 1.2 & 0.75 \\
\hline Peripheral vascular disorders & $30(2.1 \%)$ & $34(2.4 \%)$ & 1.9 & 0.61 \\
\hline Congestive heart failure & $133(9.4 \%)$ & 135 (9.5\%) & 0.5 & 0.90 \\
\hline Cardiac arrhythmia & $103(7.2 \%)$ & $107(7.5 \%)$ & 1.1 & 0.77 \\
\hline Hypertension & $201(14.1 \%)$ & $190(13.4 \%)$ & 2.2 & 0.55 \\
\hline
\end{tabular}

Other Elixhauser comorbidities matched included; pulmonary circulation disorders, other neurological disorders, chronic obstructive pulmonary disease, renal failure, liver disease, metastatic cancer, solid tumour without metastasis, rheumatoid arthritis/collagen vascular disease, coagulopathy, obesity, weight loss, fluid and electrolyte disorders, blood loss anaemia, deficiency anaemia, alcohol abuse and depression

(Table 2) for patients with diabetes. However, this risk appeared to be attenuated in 2019 with no significant change in severity of CAD in 2013 compared with 2019 (OR: 1.37 95\% C.I. 0.91, 2.07) (Table 2). No consistent significant effect of time on CAD burden in patients without diabetes was found (Table 2).

\section{Medication cohort}

Of the 760 patients with medication details available, 367 (48.0\%) also had a diagnosis of T2DM. Following propensity score weighting no significant differences between any patient covariates persisted (Table 3 ).

When diabetes medications use were examined, metformin was the most frequently reported (66.5\%), 


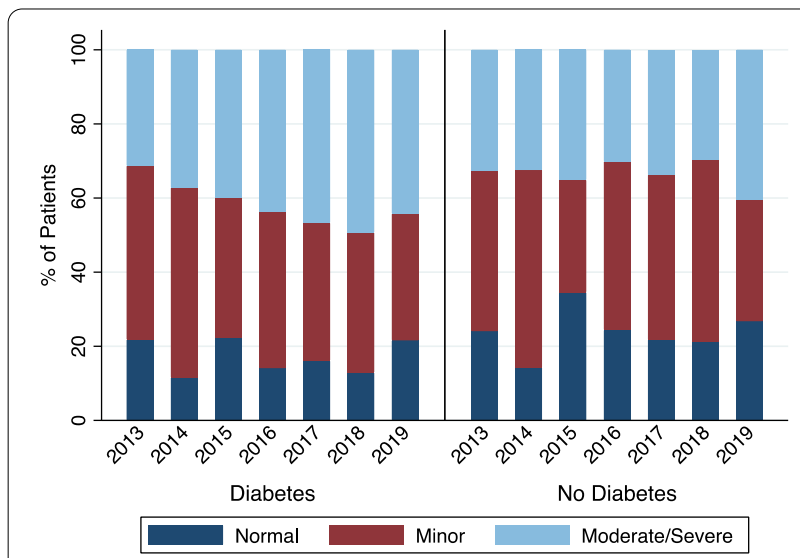

Fig. 2 Extent of CAD for patients with and without diabetes of time cohort

followed by other medications, which included thiazolidinediones and sulfonylureas (36.8\%) and insulin (23.4\%). Very few patients reported taking medications belonging to the relatively newer classes of glucoses lowering medications, the sodium-glucose transport-2 (SGLT-2) inhibitors (4.9\%) or glucagon-like peptide-1 (GLP-1) receptor agonists (3.3\%) (Additional file 1: Table S3). Patients with T2DM were more likely to take all of the traditional $\mathrm{CV}$ disease preventative therapies than patients without T2DM (Additional file 1: Table S3). The greatest difference in medication use between patients with and without T2DM was seen for the use of statins, $69.8 \%$ compared to $46.6 \%(p<0.001)$, respectively. Patients with T2DM were also more likely to be prescribed RAS inhibitors compared to those without T2DM, 64.0\% versus $49.0 \%(p<0.001)$, respectively. There was also a small but significant difference in the rates of anti-platelet drug use in patients with and without T2DM, 64.0\% versus to $49.9 \%(p=0.05)$, respectively.
Of patients with T2DM, 78.2\% $(\mathrm{n}=287)$ had evidence of angiographic CAD compared with $70.2 \%(\mathrm{n}=276)$ of patients without T2DM, $p<0.01$ (Additional file 1: Table S4). In the unweighted ordinal logistic regression model patients with T2DM were significantly more likely to have extensive CAD than patients without T2DM (OR: 1.32 95\% CI: 1.01, 1.74). Both increasing age (OR: 1.06 95\% CI: 1.04, 1.07) and being male (OR: 1.80 95\% CI: 1.36, 2.38) were associated with more extensive CAD in patients with information about medication use (Table 4). Following propensity score weighting and adjustment for the use of statins, anti-platelet drugs and RAS inhibitors, no significant difference in extent of CAD was seen between patients with and without T2DM (OR: 1.14 95\% CI: 0.85, 1.53). In the multivariate regression model both age and being male were still associated with more extensive CAD. The use of anti-platelet drugs was also associated with more extensive CAD (OR: 2.64 95\% CI: 1.93, 3.61) (Table 4).

\section{Discussion}

We found that T2DM patients have a greater burden of CAD as assessed by angiography compared to those without diabetes. Interestingly we also found that T2DM patients had more extensive CAD as assessed by angiograms performed in 2018 compared to 2013, but that possibly this trend was attenuated in 2019. The above findings need to be put into the context of a possible change in the indication or thresholds for performing coronary angiograms in people with T2DM over the observational period of the study. However, possibly the most important finding from our study is that despite a greater use of $\mathrm{CV}$ protective medications by patients with T2DM, the extent of disease within the coronary arteries, as assessed by angiography, was still greater in

Table 2 Ordinal logistic regression model for extent of CAD in the time cohort

\begin{tabular}{|c|c|c|c|c|}
\hline \multirow[t]{2}{*}{ Extent of CAD } & \multicolumn{2}{|l|}{ No diabetes } & \multicolumn{2}{|l|}{ T2DM } \\
\hline & Odds ratio $(95 \% \mathrm{Cl})$ & $P$ value & Odds ratio $(95 \% \mathrm{Cl})$ & $P$ value \\
\hline Age & $1.05(1.05,1.06)$ & $<0.001$ & $1.04(1.03,1.05)$ & $<0.001$ \\
\hline Gender (male) & $2.44(1.97,3.01)$ & $<0.001$ & $2.21(1.80,2.72)$ & $<0.001$ \\
\hline \multicolumn{5}{|l|}{ Study year } \\
\hline 2013 & Reference & & Reference & \\
\hline 2014 & $1.09(0.73,1.63)$ & 0.66 & $1.49(1.00,2.21)$ & 0.05 \\
\hline 2015 & $0.85(0.56,1.28)$ & 0.43 & $1.30(0.87,1.94)$ & 0.20 \\
\hline 2016 & $0.95(0.63,1.42)$ & 0.79 & $1.60(1.08,2.38)$ & 0.02 \\
\hline 2017 & $1.07(0.72,1.58)$ & 0.75 & $1.77(1.20,2.61)$ & $<0.001$ \\
\hline 2018 & $0.94(0.63,1.40)$ & 0.76 & $2.06(1.38,3.09)$ & $<0.001$ \\
\hline 2019 & $1.19(0.78,1.80)$ & 0.42 & $1.37(0.91,2.07)$ & 0.13 \\
\hline
\end{tabular}


Table 3 Patient demographics for the medication cohort

\begin{tabular}{|c|c|c|c|c|}
\hline Characteristics & No diabetes $(n=393)$ & T2DM $(n=367)$ & $\begin{array}{l}\text { Standardised difference } \\
(\%)\end{array}$ & $P$ value \\
\hline Age, median (IQR) & $63.9(54.4,73.0)$ & $66.6(59.9,72.7)$ & 0.5 & 0.95 \\
\hline Gender (male) & $230(58.5 \%)$ & $224(61.0 \%)$ & 1.5 & 0.84 \\
\hline \multicolumn{5}{|l|}{ Country of birth (Australian) } \\
\hline Non-Australian & $92(23.4 \%)$ & $108(29.4 \%)$ & 0.7 & \multirow[t]{3}{*}{0.85} \\
\hline Australian & $289(73.5 \%)$ & $239(65.1 \%)$ & 0.2 & \\
\hline Unknown & $12(3.1 \%)$ & $20(5.4 \%)$ & 2.1 & \\
\hline SEIFA Index, median (IQR) & $6.0(4.0,7.0)$ & $6.0(4.0,7.0)$ & 1.2 & 0.88 \\
\hline \multicolumn{5}{|l|}{ Stage of CKD } \\
\hline No known CKD & 381 (96.9\%) & $337(91.8 \%)$ & 0.3 & \multirow[t]{5}{*}{0.97} \\
\hline CKD stage 2 & $1(0.3 \%)$ & $2(0.5 \%)$ & 4.9 & \\
\hline CKD stage 3 & $5(1.3 \%)$ & $21(5.7 \%)$ & 4.0 & \\
\hline CKD stage 4 & $2(0.5 \%)$ & $3(0.8 \%)$ & 1.5 & \\
\hline CKD stage 5 & $4(1.0 \%)$ & $4(1.1 \%)$ & 1.0 & \\
\hline \multicolumn{5}{|l|}{ Indication for angiogram } \\
\hline Chest pain & $93(23.7 \%)$ & $91(24.8 \%)$ & \multirow[t]{5}{*}{0.6} & \multirow[t]{5}{*}{0.94} \\
\hline History of acute coronary event & $45(11.5 \%)$ & $42(11.4 \%)$ & & \\
\hline Breathlessness & $42(10.7 \%)$ & $32(8.7 \%)$ & & \\
\hline Positive non-invasive test & $144(36.6 \%)$ & $146(39.8 \%)$ & & \\
\hline Other & $69(17.6 \%)$ & $56(15.3 \%)$ & & \\
\hline \multicolumn{5}{|l|}{ Year of angiogram } \\
\hline 2013 & $57(14.5 \%)$ & 37 (10.1\%) & \multirow[t]{7}{*}{1.6} & \multirow[t]{7}{*}{0.84} \\
\hline 2014 & $46(11.7 \%)$ & $50(13.6 \%)$ & & \\
\hline 2015 & $53(13.5 \%)$ & $56(15.3 \%)$ & & \\
\hline 2016 & $54(13.7 \%)$ & $56(15.3 \%)$ & & \\
\hline 2017 & $60(15.3 \%)$ & $55(15.0 \%)$ & & \\
\hline 2018 & $60(15.3 \%)$ & $51(13.9 \%)$ & & \\
\hline 2019 & $63(16.0 \%)$ & $62(16.9 \%)$ & & \\
\hline Valvular disease & 39 (9.9\%) & $25(6.8 \%)$ & 2.6 & 0.77 \\
\hline Peripheral vascular disorders & $14(3.6 \%)$ & $5(1.4 \%)$ & 4.3 & 0.71 \\
\hline Congestive heart failure & $32(8.1 \%)$ & $23(6.3 \%)$ & $<0.01$ & 1.00 \\
\hline Cardiac arrhythmia & 31 (7.9\%) & $27(7.4 \%)$ & 0.9 & 0.91 \\
\hline Hypertension & $41(10.4 \%)$ & $53(14.4 \%)$ & 1.4 & 0.86 \\
\hline
\end{tabular}

Other Elixhauser comorbidities matched included; pulmonary circulation disorders, chronic obstructive pulmonary disease, renal failure, liver disease, solid tumour without metastasis, coagulopathy, weight loss, fluid and electrolyte disorders, deficiency anaemia and alcohol abuse

patients with T2DM compared to those without T2DM. However, after adjustment for medication use, we found that there was no longer any difference in the extent of CAD between patients with and without T2DM. These findings highlight the exaggerated risk that patients with T2DM are still at for developing CAD. However, they also suggest that with the greater application of traditional CV disease preventative therapies, it may be possible to reduce the extent of the CAD burden in patients with diabetes to that seen in patients without T2DM.

Of the 367 patients with T2DM and medication details available, $78 \%(n=287)$ had evidence of angiographic disease. This rate was less in patients without T2DM, of which 70\% $(n=276)$ had evidence of angiographic CAD. In our unadjusted ordinal logistic regression model, prior to accounting for the use of preventative medications, patients with T2DM were significantly more likely (by $32 \%)$ to have more extensive CAD than patients without T2DM (OR: 1.32 95\% CI: 1.01, 1.74). Following adjustment for the use of statins, RAS inhibitors and antiplatelet drugs, this significant difference in extent of CAD no longer persisted between patients with and without T2DM (OR: 1.14 95\% CI: 0.85, 1.53).

When comparing the use of traditional CV disease preventative therapies between patients with and without T2DM; statins, RAS inhibitors and anti-platelet drugs 
Table 4 Extent of CAD for the medication cohort

\begin{tabular}{lcc}
\hline & Odds Ratio $\mathbf{( 9 5 \% ~ C l )}$ & $\boldsymbol{P}$ value \\
\hline Unadjusted ordinal logistic regression model & \\
Diabetes & $1.32(1.01,1.74)$ & 0.04 \\
Age & $1.06(1.04,1.07)$ & $<0.001$ \\
Gender (male) & $1.80(1.36,2.38)$ & $<0.001$ \\
Adjusted ordinal logistic regression model following propensity score & \\
matching & & \\
Diabetes & $1.14(0.85,1.53)$ & 0.39 \\
Age & $1.05(1.03,1.06)$ & $<0.001$ \\
Gender (male) & $1.76(1.30,2.39)$ & $<0.001$ \\
Statin (yes) & $1.15(0.84,1.59)$ & 0.38 \\
Antiplatelet drug (yes) & $2.64(1.93,3.61)$ & $<0.001$ \\
RAS inhibitor (yes) & $1.37(1.01,1.86)$ & 0.04 \\
\hline
\end{tabular}

were significantly more likely to be taken by patients with T2DM. The increase in medication use for patients with T2DM compared to those without T2DM was $23 \%$ for statins, $14 \%$ for RAS inhibiting agents and $7 \%$ for antiplatelet agents. All of these differences for the uptake of $\mathrm{CV}$ preventative medication in patients with T2DM compared to those without T2DM were statistically significant. Whilst these results are encouraging, our results also emphasise that more aggressive uptake and use of $\mathrm{CV}$ protective medications, possibly earlier after a diagnosis of T2DM is made, is still required to reduce the gap between the heightened risk for more severe CAD in patients with T2DM compared to those without T2DM. Unfortunately, we lacked information on achieved lipid or blood pressure measurements to gauge whether targeting the above medications to achieve certain biochemical or clinical parameters influenced the results we report.

It is well established that risk factor modification through the optimisation of glycated haemoglobin levels and blood pressure, treatment of microalbuminuria, dietary intervention, exercise and smoking cessation are able to reduce the risk in the development and progression of vascular complications $[4,12]$. Our findings appear to be broadly consistent with those of a recent large epidemiological study which has also suggested that it is possible for patients with T2DM to eliminate their excess risk for acute myocardial infarction compared to the general population if they can achieve five risk-factor variables (glycated haemoglobin, low-density lipoprotein cholesterol, systolic blood pressure, albuminuria and smoking status) within target ranges/recommendations [5].

A number of trials, both pharmacological and epidemiological, have suggested that the use of statins and blood pressure (BP) lowering medications are most likely responsible for the change in risk for $\mathrm{CV}$ events that had been observed in recent times [13-17]. The publication of these large influential studies in the 1990's and early 2000 's and the further confirmation of the CV benefits of the above approach in later studies has led to a drastic increase in the uptake of statins and anti-hypertensive agents, in particular RAS inhibitors, for both high risk vascular patients with and without T2DM [18-20]. However, over time, some concern about side-effects has been reported regarding the use of statins [21]. If patients had been ceasing statins due to this concern, we would have expected to see the effect equally across both patient groups with and without diabetes. Given the reported side effects associated with statins, the wider use of newer approaches to treat dyslipidaemia such as the PCSK-9 inhibitors and possibly, ethyl icosapent, may result in a further decrease in the CAD burden in both patient groups with and without diabetes [22].

Targets for optimising BP lowering therapy in patients with and without diabetes still remain to be optimally defined and indeed, there has been a relaxing of BP targets for patients with diabetes over the last 10 years [23]. However, RAS inhibiting agents are often prescribed for the cardio-renal effects in addition to their use as BP lowering agents. Unfortunately, the design of our study did not allow us to follow any temporal trends in number of patients with and without T2DM taking these agents. Furthermore, the value of aspirin therapy as a primary $\mathrm{CV}$ preventative agent, when offset by potential adverse events, has also been called into question in recent times. Whether this issue has differentially affected the use of aspirin therapy in patients with and without diabetes remains to be examined.

Our analysis of patients admitted for their first coronary angiogram at a single tertiary hospital shows that the extent of CAD being detected on coronary angiogram was greater over time in patients with T2DM. This was in contrast to patients without T2DM where no significant effect on time on CAD extent was demonstrated. These findings appear to be contrary to reports of reduced rates for myocardial infarctions over recent years for patients with and without diabetes, with relative rate reductions appearing to be being larger in patients with T2DM [24]. It is therefore important to emphasise that the results we report are not based on clinical events or outcomes but rather on findings from a coronary angiogram. It is possible that the initial increase in severity of CAD burden seen in our study for patients with T2DM may represent improved CAD screening over recent years rather than suboptimal application of preventative therapies to slow disease progression within the coronary arteries. A lower threshold for performing a coronary angiogram may also exist for patients with T2DM given the 
appreciated higher risk of CAD a diagnosis of T2DM confers and a higher appreciation of asymptomatic CAD in patients with T2DM [25]. Possibly, wider use of medications such as SGLT-2 inhibitors and GLP-1 receptor agonists which have been shown to have $\mathrm{CV}$ protective effects will result in improvements in CAD burden following 2019 for patients with diabetes, however a longer duration of follow-up will be required to confirm whether the attenuation of severity in CAD is a true finding [26-29].

There were a number of limitations with this study. As we utilised hospital discharge coding data, information was not available on metabolic and blood pressure control or duration of diabetes. Therefore, we are unable to account for the effect that these preventative medications may have had on patient's risk profile. This is a single-site study, reporting on the extent of CAD in patients attending a public tertiary referral and university teaching hospital with a state-wide catchment. However, the outcome of extent of CAD may be influenced by individual differences in hospital characteristics. There may also be a small number of patients that may have incorrectly been classified as either having had or not had T2DM [30]. However, the prevalence of diabetes that we found in our study of $28 \%$ is consistent with other local studies [31]. Another limitation to consider is that this study relied on individual cardiologists reporting on the indication for angiogram and the extent of CAD without a prospective set of criteria for grading the extent of CAD; however, this is balanced by the large number of experienced cardiologists reporting results. As patients with and without T2DM were assessed in an identical fashion, it is unlikely that the extent of CAD would have been recorded disproportionately for the two groups of patients. We report on the first recorded angiogram at our hospital, it is therefore possible that a patient may have received an angiogram or coronary invasive procedure previously at a different hospital. In this case, these patients may be considered to be high risk to warrant a second angiogram and this may occur more frequently in patients with T2DM. If this was the case, these patients would almost certainly be classified as high risk vascular patients and hence been more likely to be further investigated with another angiogram at our hospital. It is presumed that the above scenario occurred more frequently in patients with diabetes given the known exaggerated risk for CAD that this group is at.

These limitations are counterbalanced by the strengths of the study which include a large number of coronary angiograms from both patients with and without diabetes over a seven year period. As it was an observational study, propensity scores were used in the regressions in order to include as many coronary angiogram results from patients with diabetes as possible allowing for a representative analysis.

\section{Conclusion}

Our findings show that the extent of disease within the coronary arteries of patients with T2DM still remains more severe compared to those without T2DM. However, it is possible that this excess burden of disease can be attenuated to the levels seen in patients without T2DM by the more aggressive uptake of traditional $\mathrm{CV}$ protective medications. These results support those of a recent large epidemiological study that suggested that aggressive risk factor modification in patients with T2DM can eliminate the excess risk for myocardial infarction compared with that of the general population [5].

\section{Abbreviations \\ CAD: Coronary artery disease; adjOR: Adjusted odds ratios; CV: Cardiovascular; T2DM: Type 2 diabetes mellitus; RAS-inhibitors: Renin-angiotensin system- inhibitors; SEIFA: Socio-Economic Indexes for Areas; ACS: Acute Coronary Event; SGLT-2: Sodium-glucose transport-2; GLP-1: Glucagon-like peptide-1; $\mathrm{BP}$ : Blood pressure; ICD-10-AM: International statistical classification of diseases and related health problems, Australian modification.}

\section{Supplementary Information}

The online version contains supplementary material available at https://doi. org/10.1186/s12872-021-02265-2.

Additional file 1: Supplementary Tables and Figures.

Additional file 2: Supplementary Methods.

\section{Acknowledgements}

We are grateful for M Masterton's assistance with editing.

\section{Authors' contributions}

KVK, RJM and VS conceived the idea of the study. KVK led the analysis with support from RJM and VS. RJM and VS supervised the analysis and generating of results. KVK drafted and finalised the paper with input from all authors. All authors contributed to the analysis, intellectual content, critical revisions to the drafts of the paper and approved the final version. KVK had full access to all the data in the study and had final responsibility for the decision to submit for publication. All authors read and approved the final manuscript.

\section{Funding}

Katerina Kiburg is supported by an Australian Government Research Training Program Scholarship.

\section{Availability of data and materials}

The data sets analysed during the current study are not publicly available because of information governance restrictions.

\section{Declarations}

Ethics approval and consent to participate

This study was approved by the St Vincent's Hospital Melbourne Human Research Ethics Committee (HREC/18/SVHM/146). 


\section{Consent for publication}

Was obtained from all the contributing authors.

\section{Competing interests}

The authors declare that they have no competing interests.

\section{Author details}

'Department of Endocrinology and Diabetes, St Vincent's Hospital Melbourne, Fitzroy, VIC, Australia. ${ }^{2}$ Department of Medicine, University of Melbourne, Fitzroy, VIC, Australia. ${ }^{3}$ St Vincent's Institute of Medical Research, Fitzroy, VIC, Australia. ${ }^{4}$ Department of Cardiology, St Vincent's Hospital Melbourne, Fitzroy, VIC, Australia. ${ }^{5}$ Department of Public Health, La Trobe University, Bundoora, Australia.

Received: 5 January 2021 Accepted: 14 September 2021 Published online: 26 September 2021

\section{References}

1. Diabetes Control Complications Trial Research Group. Effect of intensive diabetes management on macrovascular events and risk factors in the diabetes control and complications trial. Am J Cardiol. 1995;75:894-903.

2. Wan EYF, Fung CSC, Jiao FF, Yu EYT, Chin WY, Fong DYT, et al. Five-year effectiveness of the multidisciplinary risk assessment and management programme-diabetes mellitus (RAMP-DM) on diabetes-related complications and health service uses - a population-based and propensitymatched cohort study. Diabetes Care. 2018:41(1):49-59.

3. UK Prospective Diabetes Study Group. Intensive blood-glucose control with sulphonylureas or insulin compared with conventional treatment and risk of complications in patients with type 2 diabetes (UKPDS 33). The Lancet. 1998;352(9131):837-53.

4. Gæde P, Vedel P, Larsen N, Jensen GV, Parving H-H, Pedersen O. Multifactorial intervention and cardiovascular disease in patients with type 2 diabetes. N Engl J Med. 2003;348(5):383-93.

5. Rawshani A, Rawshani A, Franzén S, Sattar N, Eliasson B, Svensson A-M, et al. Risk factors, mortality, and cardiovascular outcomes in patients with type 2 diabetes. N Engl J Med. 2018;379(7):633-44.

6. Ogurtsova K, da Rocha FJ, Huang Y, Linnenkamp U, Guariguata L, Cho N, et al. IDF diabetes atlas: global estimates for the prevalence of diabetes for 2015 and 2040. Diabetes Res Clin Pract. 2017;128:40-50.

7. Australia Bureau of Statistics. National health survey: first results, 2014-2015. Cat. no. 4364.0. 55.001 [Online]. ABS. 2015.

8. Development ACFC. The international statistical classification of diseases and related health problems, Australian modification (ICD-10-AM). 10th edn. Development ACfC, editor 2017.

9. Elixhauser A, Steiner C, Harris DR, Coffey RM. Comorbidity measures for use with administrative data. Med Care. 1998;36:8-27.

10. Austin PC. Goodness-of-fit diagnostics for the propensity score model when estimating treatment effects using covariate adjustment with the propensity score. Pharmacoepidemiol Drug Saf. 2008;17(12):1202-17.

11. Austin PC, Stuart EA. Moving towards best practice when using inverse probability of treatment weighting (IPTW) using the propensity score to estimate causal treatment effects in observational studies. Stat Med. 2015;34(28):3661-79.

12. Stratton I, Cull C, Adler A, Matthews D, Neil H, Holman R. Additive effects of glycaemia and blood pressure exposure on risk of complications in type 2 diabetes: a prospective observational study (UKPDS 75). Diabetologia. 2006;49(8):1761-9.

13. Pyörälä K, Pedersen TR, Kjekshus J, Faergeman O, Olsson AG, Thorgeirsson $\mathrm{G}$. Cholesterol lowering with simvastatin improves prognosis of diabetic patients with coronary heart disease: a subgroup analysis of the Scandinavian Simvastatin Survival Study (4S). Diabetes Care. 1997;20(4):614-20.

14. Gæde P, Pedersen O. Intensive integrated therapy of type 2 diabetes: implications for long-term prognosis. Diabetes. 2004;53(suppl 3):S39-47.

15. Colhoun HM, Betteridge DJ, Durrington PN, Hitman GA, Neil HAW, Livingstone SJ, et al. Primary prevention of cardiovascular disease with atorvastatin in type 2 diabetes in the Collaborative Atorvastatin Diabetes Study (CARDS): multicentre randomised placebo-controlled trial. The Lancet. 2004;364(9435):685-96.

16. Gasowski J, Birkenhäger WH, Staessen JA, de Leeuw PW. Benefit of antihypertensive treatment in the diabetic patients enrolled in the Systolic Hypertension in Europe (Syst-Eur) trial. Cardiovasc Drugs Ther. 2000;14(1):49-53.

17. Heart Outcomes Prevention Evaluation Study Investigators. Effects of ramipril on cardiovascular and microvascular outcomes in people with diabetes mellitus: results of the HOPE study and MICRO-HOPE substudy. The Lancet. 2000;355(9200):253-9.

18. Yusuf S, Lonn E, Pais P, Bosch J, Lopez-Jaramillo P, Zhu J, et al. Blood-pressure and cholesterol lowering in persons without cardiovascular disease. N Engl J Med. 2016;374(21):2032-43.

19. Zoungas S, Chalmers J, Neal B, Billot L, Li Q, Hirakawa Y, et al. Follow-up of blood-pressure lowering and glucose control in type 2 diabetes. N Engl J Med. 2014;371(15):1392-406.

20. Gæde P, Oellgaard J, Carstensen B, Rossing P, Lund-Andersen H, Parving $\mathrm{H}-\mathrm{H}$, et al. Years of life gained by multifactorial intervention in patients with type 2 diabetes mellitus and microalbuminuria: 21 years follow-up on the Steno-2 randomised trial. Diabetologia. 2016;59(11):2298-307.

21. Sivashanmugarajah A, Fulcher J, Sullivan D, Elam M, Jenkins A, Keech A. Suggested clinical approach for the diagnosis and management of 'statin intolerance'with an emphasis on muscle-related side-effects. Int Med J. 2019:49(9):1081-91.

22. Sabatine MS, Leiter LA, Wiviott SD, Giugliano RP, Deedwania P, De Ferrari GM, et al. Cardiovascular safety and efficacy of the PCSK9 inhibitor evolocumab in patients with and without diabetes and the effect of evolocumab on glycaemia and risk of new-onset diabetes: a prespecified analysis of the FOURIER randomised controlled trial. Lancet Diabetes Endocrinol. 2017:5(12):941-50.

23. De Boer $I H$, Bangalore $S$, Benetos A, Davis AM, Michos ED, Muntner P, et al. Diabetes and hypertension: a position statement by the American Diabetes Association. Diabetes Care. 2017;40(9):1273-84.

24. Gregg EW, Li Y, Wang J, Rios Burrows N, Ali MK, Rolka D, et al. Changes in diabetes-related complications in the United States, 1990-2010. N Engl J Med. 2014;370(16):1514-23.

25. Arora S, Ofstad AP, Ulimoen GR, Birkeland Kl, Endresen K, Gullestad L, et al. Asymptomatic coronary artery disease in a Norwegian cohort with type 2 diabetes: a prospective angiographic study with intravascular ultrasound evaluation. Cardiovasc Diabetol. 2019;18(1):26.

26. Marso SPDG, Brown-Frandsen K, Kristensen P, Mann JF, Nauck MA, Nissen SE, Pocock S, Poulter NR, Ravn LS, Steinberg WM, Stockner M, Zinman B, Bergenstal RM, Buse JB. LEADER steering committee; LEADER trial investigators Liraglutide and cardiovascular outcomes in type 2 diabetes. N Engl J Med. 2016:375(4):311-22.

27. Wanner CIS, Lachin J, Fitchett D, von Eynatten M, Mattheus M, Johansen $\mathrm{O}$, Woerle H, Broedl U, Zinman B. EMPA-REG OUTCOME investigators empagliflozin and progression of kidney disease in type 2 diabetes. $\mathrm{N}$ Engl J Med. 2016;375(4):323-34.

28. Marso SP, Daniels GH, Brown-Frandsen K, Kristensen P, Mann JFE, Nauck MA, et al. Liraglutide and cardiovascular outcomes in type 2 diabetes. N Engl J Med. 2016:4:311.

29. Wanner C, Inzucchi SE, Lachin JM, Fitchett D, von Eynatten M, Mattheus $M$, et al. Empagliflozin and progression of kidney disease in type 2 diabetes. N Engl J Med. 2016;4:323.

30. Henderson T, Shepheard J, Sundararajan V. Quality of diagnosis and procedure coding in ICD-10 administrative data. Med Care. 2006:44:1011-9.

31. Bach LA, Ekinci El, Engler D, Gilfillan C, Hamblin PS, Maclsaac RJ, et al. The high burden of inpatient diabetes mellitus: the Melbourne public hospitals diabetes inpatient audit. Med J Aust. 2014;201(6):334-8.

\section{Publisher's Note}

Springer Nature remains neutral with regard to jurisdictional claims in published maps and institutional affiliations. 